Bidik

Vol. 1 No. 1 Oktober 2020

$27-31$

\title{
Pelatihan Konsep Audio Visual Dalam Pengembangan Budaya Melayu Di Desa Tualang
}

\author{
Jefrizal $^{*}$, Iik Idayanti, Ridwan \\ Fakultas Ilmu Budaya, Universitas Lancang Kuning \\ *Email : jefrizal@unilak.ac.id
}

\begin{abstract}
The purpose of this training is to provide an understanding of general audio-visual information and give tips to explore ideas from the potential of local art and culture content to be developed into content on social media. To achieve this, stages are needed, including exposure to general audio-visual information and exposure to tips to explore ideas from the potential of local art and culture content.
\end{abstract}

Keywords: Audio Visual, Malay culture; Training

\begin{abstract}
Abstrak
Tujuan dari pelatihan ini adalah memberikan pemahaman tentang informasi umum audio visual dan berbagi kiat-kiat menggali ide dari potensi seni budaya konten local yang ada untuk dikembangkan menjadi konten di sosial media. Untuk mencapai ini, maka diperlukan tahapan diantaranya, pemaparan tentang informasi umum audio visual dan pemaparan kiat-kiat menggali ide dari potensi seni budaya konten lokal.
\end{abstract}

Kata kunci: Audio Visual, budaya Melayu; Pelatihan

\section{Pendahuluan}

Youtube.com, merupakan salah satu situs website yang menggunakan internet untuk menjalankan fiturnya, dengan Youtube, seorang pengguna dapat memposting atau menampilkan video maupun animasi agar dapat dilihat dan dinikmati orang banyak.

Laman Youtube merupakan situs berbagi informasi, media sharing. Dapat dimaknai sebagai jenis media sosial yang menfasilitasi penggunanya untuk berbagi informasi, mulai dari video, audio, dan gambar. Youtube media sosial yang mulai diminati oleh banyak orang beberapa tahun yang lalu. Media soial ini bahkan telah dijadikan sebagai laman bisnis kreatifitas. Sehingga saat ini youtube bukan hanya sebuah situs, karena dengan youtube, seseorang dapat menghasilkan uang.

Pekerjaan pada zaman sekarang kian lama kian pesat, kecanggihan teknologi dan informasi sudah merajai di berbagai bidang kehidupan manusia. Sudah memasuki industri kreatif dan inovatif. Semakin banyak industri teknologi kreatif yang membuka peluang pekerjaan bagi anak-anak milenial yang masih memiliki pemikiran dan kreasi yang sangat luas. Salah satu industri kreatif yang dijadikan bisnis berskala dunia dan sangat digemari di Indonesia adalah Youtube.com. 
Dengan perkembangannya yang pesat ini,makin banyak orang membuat akun youtube untuk dijadikan bisnis sebagai sumber penghasilan. Peluang ini seharusnya dijadikan oleh insan-insan budaya untuk turut serta dalam kesempatan yang memiliki banyak peluang ini. Tidak hanya peluang materi, tetapi juga sebagai upaya untuk mengapayekan khazanah budaya yang begitu kaya di Riau ini.

Masalah utama yang dihadapi mitra adalah kurangnya informasi terkait dengan ide untuk membuat konten audio visual di laman media sosial. Selain tu, mitra juga belum memahami ilmu dasar-dasar audio visual. Sehingga ada hasrat dan keinginan yang kuat tetapi tidak dapat tersalurkan dengan baik.

Beberapa diantaranya, sudah ada yang pernah mencoba untuk membuat konten audio visual namun tidak bertahan lama karena kehabisan ide dan gagasan. Jadi kesimpulannya, masalah mitra terletak pada kekurangtahuan tentang bagaimana menggali potensi-potensi khazanah budaya yang ada untuk dijadikan bahan dalam membuat konten audio visual.

\section{Pedekatan Pelaksanaan Program}

Kegiatan $\mathrm{I}_{b} \mathrm{~m}$ diperuntukkan bagi generasi muda di Desa Tualang, termasuk diantaranya alumni Prodi Sastra Daerah FIB Unilak. Peserta yang mengikuti pelatihan berjumlah total 20 orang. Beberapa diantaranya ada yang berstatus sebagai siswa-siswi SMA Negeri 2 Tualang.

Pelaksanaan kegiatan meliputi beberapa tahap sebagai berikut:

1. Pemaparan tentang informasi umum audio visual

Pada sesi ini, mitra diberi pemahaman dasar tentang produk audio visual. Saat ini, audio visual bukanlah sesuatu yang sulit untuk dihasilkan. Karena dengan menggunakan handphone saja sudah bisa menghasilkan produk audio visual yang standar. Khususnya untuk konten di sosial media.

2. Pemaparan kiat-kiat menggali ide dari potensi seni budaya konten local.

Pada sesi ini dijelaskan terkait dengan menggali ide dan gagasan yang ada di sekitar mitra terutama potensi dan khazanah seni budaya yang ada. Mulai dari produk seni, budaya, lokal konten, alam, kerajinan, adat tradisi.

Pada sesi ini juga diberi pemahaman bagaimana mengemas sebuah ide untuk dijadikan konten yang menarik untuk dionton sekaligus ada nilai edukasinya.

\section{Pelaksanaan Program}

Kegiatan pelatihan dilaksanakan pada tanggal 12 Juni 2020. Kegiatan dipusatkan di taman Wisata Tolok Jangkang Desa Tualang. Dimulai pukul 10:00 17:00. Dikuti oleh 20 peserta yang terdiri dari generasi muda Desa Tualang, alumni dan juga beberapa siswa-siswi SMA Negeri 2 Tualang.

Kegiatan pelatihan yang dilangsungkan memberikan hasil dan manfaat yang berguna bagi peserta. Hal tu dapat diketahui dari Pre-test dan post-test yang dilakukan. Selain itu juga dapat dilihat dari minat dan bersemangat para peserta dalam mengikuti pelatihan yang telah dilaksanakan. Sejak awal, hampir seluruh peserta menyatakan kurang mengetahui cara mengali ide dan gagasan untuk konten d sosial 
media. Meskipun ada beberapa yang sudah mulai membuat konten di Laman Youtube.

\section{Gambar 1 Pelaksanaan Pengabdian}
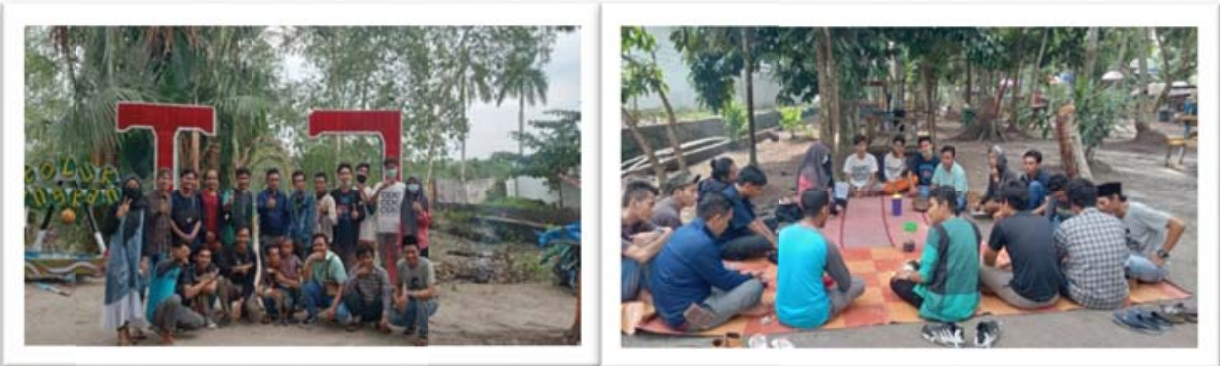

Begitu juga dengan kesadaran, tidak banyak peserta yang menyadari kekayaan khazanah potensi seni budaya yang ada di desa mereka. Kesemua itu sebenarnya merupakan modal untuk dijadikan konten di laman sosial media.

Tabel 1 Evaluasi Pre test

\begin{tabular}{|c|l|c|c|}
\hline No & \multicolumn{1}{|c|}{ Topik Test } & Ya & Tidak \\
\hline 1 & $\begin{array}{l}\text { Pengetahuan tentang laman } \\
\text { Youtube }\end{array}$ & 14 & 6 \\
\hline 2 & $\begin{array}{l}\text { Potensi khazanah seni budaya di } \\
\text { desa Tualang }\end{array}$ & 2 & 18 \\
\hline 3 & Pengetahuan mengemas konten & 5 & 18 \\
\hline 4 & Cara mengggali ide dan gagasan & 2 & 18 \\
\hline 5 & $\begin{array}{l}\text { Pengetahuan tentang dasar audio } \\
\text { visual }\end{array}$ & 2 & \\
\hline
\end{tabular}

Berdasarkan tabel mengenai pretest di atas, dapat disimpulkan bahwa ada banyak pesera yang tidak memiliki pengetahuan tentang dasar konsep audio visual. Tidak memiliki kesadaran akan potensi khazanah seni budaya yang dimiliki, tidak mengetahui cara menggali ide dan gagasan serta mengemasnya menjadi konten di youtube. Padahal, potensi lokalitas yang dimiliki setiap daerah memiliki corak tersendiri untuk dapat dikemas dalam sebuah konten yang menarik untuk ditawarkan kepada khalayak. Tidak perlu meniru-niru konten yang sudah banyak tayang di laman youtube saat ini.

Sedangkan hasil dari post-test menunjukkan perbedaan yang signifikan dibandingkan hasil pretest. Dapat dilihat dari tabel di bawah ini:

Tabel 1 Evaluasi Post test

\begin{tabular}{|c|l|c|c|}
\hline No & \multicolumn{1}{|c|}{ Topik Test } & Ya & Tidak \\
\hline 1 & $\begin{array}{l}\text { Pengetahuan tentang laman } \\
\text { Youtube }\end{array}$ & 20 & - \\
\hline 2 & $\begin{array}{l}\text { Potensi khazanah seni budaya di } \\
\text { desa Tualang }\end{array}$ & 20 & - \\
\hline
\end{tabular}


Bidik Vol. 1 No. 1 Oktober 2020 | 30

\begin{tabular}{|c|l|c|c|}
\hline 3 & Pengetahuan mengemas konten & 20 & - \\
\hline 4 & Cara mengggali ide dan gagasan & 20 & - \\
\hline 5 & $\begin{array}{l}\text { Pengetahuan tentang dasar audio } \\
\text { visual }\end{array}$ & 20 & - \\
\hline
\end{tabular}

Berdasarkan tabel di atas, dapat dijelaskan pula bahwa setelah mengikuti pelatihan hingga ke akhir, seluruh peserta jadi paham dan mengetahui capaian dari pelatihan yang dilakukan. Meskipun pemahaman yang diketahui hanyalah dasar dan perlu untuk langsung diaplikasikan. Seluruh peserta ketika ditanya di sesi akhir terkait dengan potensi kahzanah seni yang dapat diolah di desa Tualang, masing-masing dapat mengiditifikasikannya.

Dari pelatihan ini dapat juga disimpulkan, betapa banyak generasi muda yang hari ini, tidak menyadari kekuatan dan potensi lokalitas yang mereka miliki. Sebuah keadaan, apa yang mereka miliki, tidak dianggap berharga dan menarik sehingga mereka lebih senang melihat apa yang dimiliki oleh orang lain atau produk budaya dari luar.

Setelah diberi pemahaman, barulah mereka sadar betapa, khazanah dan potensi lokalitas yang kita miliki sendiri begitu banyak yang belum digali, belum dikembangkan untuk diperkenalkan kepada khalayak luar.

\section{Luaran yang Dicapai}

Luaran yang dicapai dalam kegiatan ini adalah pemahaman para peserta terhadap dasar-dasar konsep audio visual dikaitkan dengan pengembangan budaya Melayu. Pemahaman ini menjadi penting mengingat kurangnya kesadaran generasi hari ini tentang peluang untuk menjadikan laman media sosial sebagai peluang usaha sekaligus media penyebaran informasi.

Pasca pelatihan dapat pula dilihat, beberapa dari peserta mulai membuat konten youtube dengan kemasan yang mereka konsep sendiri. Tentu hal ini menjadi kabar yang sangat menggembirakan. Karena pelatihan yang dilaksanakan tidak akan berarti apa-apa apabila tidak dipraktikkan langsung di lapangan.

\section{Refleksi Capaian Program}

Kegiatan Pelatihan Konsep Audio Visual dalam Pengembangan Budaya Melayu berjalan lancar. Tidak ada halangan yang berarti, peserta pun hadir dan mengikuti pelatihan dari awal sampai dengan selesai.

Antusias peserta dalam pelatihan ini juga menunjukkan hal yang menggembirakan. Artinya, penyampaian materi yang dibuat sederhana dapat dicermati oleh peserta, dan peserta juga jadi memahami capaian dari pelatihan ini bahkan ada beberapa diantaranya, kemudian langsung mempraktikkan pemamahan yang didapat dari pelatihan ini. Dua hari setelahnya, mereka membuat konten di laman youtube. 


\section{Penutup}

Dari kesimpulan di atas, ada beberapa hal yang perlu digaris bawahi adalah berupa saran:

1. Sebaiknya organisasi di desa menggalakan diskusi dan pelatihan seni budaya secara berkala, agar ada wadah bagi generasi muda di kampung untuk saling berbagi dan berdiskusi

2. Disarankan juga bagi mereka untuk membuat grop WA, agar kiranya dapat saling berbagi informasi tentang karya yang mereka buat dan saling mendukung dalam bentuk apapun.

\section{Daftar Pustaka}

Mahfud Mahdudz, 2005. Pengantar Bisnis Modern. Andi, Yogyakarta.

Aditya Jatiagung Nirwana, 2016 Media Baru, Lahan Bagi Pencipta Konten Kreatif.

Universitas Mercu Buana, Yogyakarta.

Budhisantoso, S, 1982. Kesenian dan Nilai-nilai Budaya. Dep. Pendidikan dan

Kebudayaan, Jakarta.

UNESCO. (2003). Charter on the preservation of the digital heritage. Paris: UNESCO.

Perundangan-undangan:

Undang-Undang Dasar 1945 Amandemen Ke-IV

Undang-Undang Nomor 11 Tahun 2010 tentang Cagar Budaya. 